\title{
Chemical Reactivity Perspective into the Group 2B Metals Halides
}

\author{
Alimet Sema Özen*, Zehra Akdeniz
}

Faculty of Science and Letters, Piri Reis University, 34940 Tuzla, Istanbul

*asozen@pirireis.edu.tr

Table 1S. Dimerization Energies (|DE|) in kcal/mol for Group 2B Heterodimers $\mathrm{MX}_{2}{ }^{\cdots} \mathrm{MY}_{2}$ where $\mathrm{M}=\mathrm{Zn}, \mathrm{Cd}, \mathrm{Hg}$ and $\mathrm{X}=\mathrm{F}, \mathrm{Cl}, \mathrm{Br}$, I.

\begin{tabular}{|c|c|c|c|c|}
\hline & $\begin{array}{c}\mathrm{HgX}_{2} \cdots \mathrm{HgY}_{2} \\
(\mathrm{MWB})\end{array}$ & $\mathrm{CdX}_{2} \cdots \mathrm{CdY}_{2}$ & $\mathrm{ZnX}_{2} \cdots \mathrm{ZnY}_{2}$ & $\begin{array}{c}\mathrm{HgX}_{2} \cdots \mathrm{HgY}_{2} \\
(\mathrm{MHF})\end{array}$ \\
\hline $\mathrm{MBr}_{2}-\mathrm{MI}_{2}$ & 1.478 & 12.896 & 15.123 & 17.314 \\
\hline $\mathrm{MCl}_{2}-\mathrm{MI}_{2}$ & 4.007 & 12.754 & 15.229 & 17.975 \\
\hline $\mathrm{MCl}_{2}-\mathrm{MBr}_{2}$ & 4.339 & 13.557 & 16.595 & 18.867 \\
\hline $\mathrm{MF}_{2}-\mathrm{MI}_{2}$ & 4.795 & 21.117 & 23.022 & 26.938 \\
\hline $\mathrm{MBr}_{2}-\mathrm{MF}_{2}$ & 5.049 & 21.639 & 23.994 & 27.617 \\
\hline $\mathrm{MCl}_{2}-\mathrm{MF}_{2}$ & 7.351 & 21.118 & 23.748 & 27.882 \\
\hline
\end{tabular}

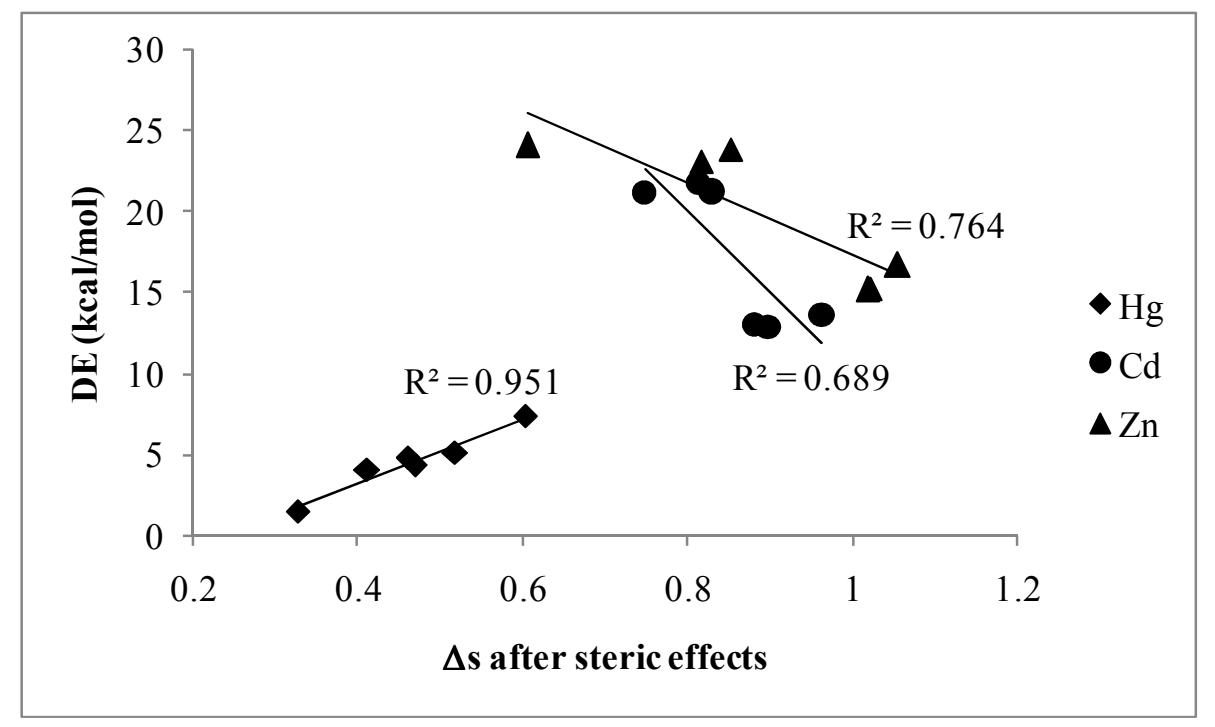

Figure 1S. Softness matching-4: $\Delta \mathrm{s}$ between average $M\left(\mathrm{~s}^{+}\right)$and average $\mathrm{X}\left(\mathrm{s}^{-} / \mathrm{r}_{\mathrm{X}}\right)$ (after elimination of the steric effects for halogens) versus dimerization energy in $\mathrm{kcal} / \mathrm{mol}$ for the heterodimers $(\mathrm{M}=\mathrm{Zn}, \mathrm{Cd}, \mathrm{Hg}$ and $\mathrm{X}=\mathrm{F}, \mathrm{Cl}, \mathrm{Br}, \mathrm{I})$. 